\title{
Test bolus measurement: effects of the respiratory position on bolus arrival time and signal-intensity-time curve quality
}

Rolf Janka • Marius Rudy • Michael Lell •

Michael Uder • Werner Bautz • Evelyn Wenkel

Published online: 2 October 2007

(C) ESMRMB 2007

Erratum to: Magn Reson Mater Phy

DOI 10.1007/s10334-007-0080-4

The names of the authors have been represented incorrectly in the original publication.

The correct representation of author names is as follows:

Rolf Janka, Marius Rudy, Michael Lell, Michael Uder, Werner Bautz, Evelyn Wenkel.

The online version of the original article can be found under doi:10.1007/s10334-007-0080-4.

R. Janka ( $\varangle)$ · M. Lell · M. Uder · W. Bautz · E. Wenkel Department of Radiology, University of Erlangen,

Maximiliansplatz 1, Erlangen 91054, Germany

e-mail: rolf.janka@idr.imed.uni-erlangen.de

M. Rudy

Department of Radiology, Klinikum Nuernberg,

Nuremberg, Germany 